\title{
Claiming Health as a Public Good in the Post-COVID-19 Era
}

\author{
Salma M. Abdalla ${ }^{1} \cdot$ Nason Maani $^{1} \cdot$ Catherine K. Ettman ${ }^{1,2} \cdot$ Sandro Galea $^{1}$
}

Published online: 10 November 2020

(c) Society for International Development 2020

\begin{abstract}
The global response to COVID-19 has been uneven and disappointing in the vast majority of countries. The United States has borne the largest absolute burden of disease globally, as COVID-19 exploited pre-existing poor population health among Americans to spread rapidly, with devastating consequences. Why does the country that spends the most on healthcare in the world have one of the worst responses to COVID-19? We argue that this is because the United States conception of health is predominantly focused on healthcare, an overwhelming investment in developing drugs and treatments, and an underinvestment in the foundational conditions that keep people healthy. COVID-19 has exposed the limits of this approach to health. In order to prevent COVID-19 and future such pandemics, we must create the conditions that can keep population-level health threats at bay. This means addressing the conditions that shape health, including economics, employment, community networks, racial disparities, how we treat older adults, and the physical layout of our communities. To do so means acknowledging health as a public good, as a transnational project with countries working together to build a healthier world. It also means acknowledging that everyone has a right to health. These aspirations should become core to the global community's health aspirations in the post-COVID-19 era.
\end{abstract}

Keywords COVID-19 $\cdot$ Public good $\cdot$ Social determinants of health $\cdot$ Global public health

The COVID-19 pandemic presents an unprecedented global challenge with more than 33 million cases and a million related deaths at the time of writing. However, the burden of the pandemic has not been evenly distributed across the world, with a few countries, including the United States, accounting for the majority of cases and deaths.

While many factors contributed to the uneven COVID19 toll on countries around the globe, some countries have done better than others in suppressing and mitigating the consequences of the pandemic. Investment in measures that reduce the physical consequences of the COVID-19, interrupting the transmission of the virus, and mitigating the societal costs of such measures played a major role in shaping the trajectory of the pandemic in several countries (Han et al. 2020).

However, perhaps more fundamentally, COVID-19 exposed the limits of our current approach to health, highlighting the importance of tackling the foundational

Salma M. Abdalla

abdallas@bu.edu

Boston University School of Public Health, Boston, USA

2 Brown University School of Public Health, Providence, USA determinants of health in addressing such crises. In this essay, we argue that claiming health as a public good is an imperative first step to mitigate the consequences of the pandemic and creating a healthier post-COVID-19 world. We will use the United States as a case example to illustrate how the national failures in handling COVID-19 exemplify the need for a broader rethinking of health.

\section{COVID-19 in the United States}

The United States has the highest number of COVID-19 cases and deaths in the world, with more than 200,000 COVID-19-related loss of life (Johns Hopkins Coronavirus Resource Center 2020). Minorities and lower income groups, in particular, have experienced a disproportionate toll of cases and deaths (Tai et al. 2020). The United States also experienced substantial economic and social consequences due to both the pandemic and the policies implemented to limit the spread of COVID-19. For example, by April 2020, there were 36 million jobs lost and more than a third of those were among people with an annual income of $\$ 40,000$ or less (Galea and Abdalla 2020). Between March 
and April, the prevalence of depression symptoms in the United States was more than 3-times higher compared to national estimates in 2018. People with lower social or economic resources, those with greater exposure to COVID-19 related stressors (e.g. job loss due to the pandemic) reported a greater burden of depression symptoms (Ettman et al. 2020).

Despite these realities, the federal and state response to COVID-19 has been patchy, with some good decisions but also many stumbles. While much has been made of the shortcomings of the official federal response to the pandemic, and how that contributed to the burden of COVID-19 in the country, the acute response was very much only part of the problem. American vulnerability to this pandemic was sealed long before COVID-19 emerged because of its chronic underinvestment in the foundational forces that shape health. Longstanding conditions of poverty, increasing income inequality, racism, lack of health care access, unstable housing, lack of quality education, and other factors that produce poor health in society have made some people far likelier to catch the disease than others (Galea et al. 2011). COVID-19 exploited existing health disparities, using the poor health of vulnerable populations to gain a foothold (Maani and Galea 2020b). The pandemic simply revealed these fundamental facts, exposing long-standing inequities. It is also not exactly news, of course, that these conditions undermine health (Braveman et al. 2011; WHO Commission on Social Determinants of Health 2008). So why have we so long accepted them?

\section{The United States was Particularly Susceptible to COVID-19}

We argue that the central reason the United States has long accepted health inequities as the embodiment of underlying socioeconomic and racial inequalities is that Americans treat health as a commodity, something to buy and sell. Americans have come to see health as health care-as the doctors and medicines that treat the sick, rather than the state of not being sick to begin with. That is then a short step away to seeing health as something that can be bought more by those with more resources, and as an asset that benefits from investment in selective approaches that help those with the most resources. A net result of this thinking is that the vast majority of US health spending has gone to developing new drugs and treatments that are particularly useful to those at the extreme end of life, those who have not had the misfortune of succumbing at younger ages to preventable illness. For example, between 1970 and 2017, there was an almost six-fold increase in healthcare expenditure from $\$ 74.6$ billion to $\$ 3.5$ trillions (Kamal and Cox 2018). While there is no question that health care matters, particularly for those who are in older age groups, it is also true that the contribution of health care to the health of the population pales in comparison with investment in the forces that create a healthier world, that prevent disease to begin with.

Unfortunately, and counter to what would be needed to create a healthier country, investment in public health and other foundational determinants has been in decline over the past few decades (Maani and Galea 2020a, b). Historically, spending on public health has been consistently less than $3 \%$ of the total health expenditure (Himmelstein and Woolhandler 2016). Additionally, the United States spent far less, and is spending ever less, than other high-income countries on the conditions that promote health. When compared to peer countries, the United States unfailingly performs worse on the level of investment in social or economic conditions foundational to health. It is estimated that, given the country's level of wealth, spending on social investment is at least $\$ 1.6$ trillion less than needed to create healthy conditions for the population. Between 1962 and 2017, the share of federal spending on social and economic investments such as education decreased by 59\%. During the same period, spending on programmes that provide healthcare-related costs increased by $162 \%$ (The Concord Coalition 2018). Therefore, the United States is both investing ever more money in healthcare, and ever less in the conditions that create health, premised fundamentally on an understanding of health as a private good, where individuals bear little, if any, responsibility for the health of the collective. It is thus not surprising that emerging research shows that, while the health of those with the most resources in the United States has improved over the past two decades, the health of the remainder of the population has stagnated, if not worsened (Abdalla et al. 2020).

\section{COVID-19 Highlights the Limitations in our Approach to Health in the United States}

COVID-19 has exposed the limits of this approach to health. It has shown that the health of individuals is interconnected in a way that is unprecedented. The majority of the United States population came to realize, perhaps for the first time in a long time, that their health was tied to the health of others. It matters greatly how others feel, what they do, where they go, whether they have the resources they need to be safe and healthy. Because if everyone cannot be healthy, no one cannot rest easy in their own health.

The few successful national steps the United States has taken to mitigate COVID-19 had little to do with medicine. This is because medicine, for all its uses, has little bearing on prevention, barring, in this case, the eventual development of effective vaccines. Doctors and drugs can help those who catch COVID-19, but the overwhelming focus these 
past months had been on attempting to ensure that the virus does not spread among the population.

In order to prevent COVID-19, there needs to be a collective realization that that Americans, together, must create the conditions for keeping it at bay. This means addressing the disease at the level of the conditions that shape health such as economics, employment, community networks, racism and racial disparities, treatment of older adults, and the physical layout of communities and neighborhoods. Early governmental efforts to tackle COVID-19, such as the direct financial assistance authorized by the federal government, aimed to address some of these factors but they have not been continued or expanded on. To the contrary, many of these measures were recently abandoned, and much of the discourse around tackling COVID-19 became mired in partisan divides. This has been amply apparent in a range of policy discussions. An example is the arguments around the efficacy of masks to reduce the transmission of the virus, which quickly became centered around individual choices, stratified by partisan affiliation, rather around the collective benefits of such an approach.

It became clearer than ever in the past year that if the United States is to overcome the COVID-19 pandemic, there is a need to reframe the conversation and act collectively, to ensure everyone can access the resources necessary for health. This would require acknowledging health as a public good.

\section{What are Public Goods?}

Public goods are resources that do not lend themselves to market production, they benefit everyone, and are sustained by collective investment (Galbraith 1998). Public goods can also be socially constructed rather than inherent (Deneulin and Townsend 2006). They include, among others, parks, public schools, fire stations, national security, the highway system, and the environment. When something is labelled as a public good, that is because it is too critical to be accessible only to those who can pay for it. Societies then take steps, together, to ensure the resource is widely available to every member of the population.

To illustrate, let us consider firefighting. The traditional role of firefighting, which dates back to the Roman era, has been, unsurprisingly, to put out fires. More recently, however, the focus has been on fire prevention. In the United States, starting roughly after the Great Chicago Fire in the nineteenth century, fire departments have helped communities adopt strategies to stop fires from breaking out. This generally involves a combined approach of building safer houses and creating a culture of prevention by educating the public on safety best practices.
These efforts are funded by the communities themselves. Americans have come to see them as a public good and invest in them collectively. When it comes to fire prevention, this investment has paid off. In 1977, there were 5865 civilian deaths caused by home fires in the United States. In 2016, there were 2735 (Haynes 2017). The example of firefighting seems apposite to the present moment. The inability to invest in health as a public good in the United States has created the conditions that increased the vulnerability of the nation to COVID-19. The path forward for a heathier population in the United States will require acknowledging the limitations of the current national understanding of health and embracing health as a public good.

\section{Claiming Health as a Global Public Good}

The global population is in the midst of a health crisis that has effectively lit the world on fire. It has now been about eight months since COVID-19 first entered the world's consciousness. During that time, it has spread around the globe, threatening the physical and mental health of populations. At the same time, the physical distancing measures adopted to slow the spread of the disease have created social and economic disruptions that will likely be with the global population for many years to come.

While there have been multiple efforts to frame health as global public good in recent years, none have gained the traction one would hope they have to make a difference (Feachem and Sachs 2002; Feachem and Medlin 2002; Smith 2003; Smith et al. 2003; Smith and MacKellar 2007; Stein and Sridhar 2017; Moon et al. 2020). The COVID-19 pandemic may be the catalyst needed to push these efforts forward. The pandemic highlighted the need to reframe the conversation around health and put forth the role health plays in shaping the global social and economic conditions (Bonaccorsi et al. 2020; World Bank 2020).

For a long time, the world has hesitated to see health as a global public good because of the consequences of such decision. It would imply a responsibility for addressing health at every level of society, for building a world that generates health. It would call on decision-makers to place health at the heart of global trade, policymaking, industry, urban design, even geopolitics. It also means acknowledging that everyone has a right to health. A world where any number of people are consigned to poor health is unacceptable. One could liken the global population to a single human body. Within this organism, millions of diverse, specialized cells link to play their part in maintaining a healthy system. An ailing part of this system cannot be ignored, because it affects the whole.

COVID-19 has reminded the world that the health of the few is tied to the health of the many. Perhaps most 
importantly, this brings home the observation that supporting the health of those who are most vulnerable is protective not only of their health, but also of the health of the general population. This realization has begun to influence the health conversation, and attendant action related to COVID-19. In the United States, for example, the pandemic created a new focus on the populations most at risk of the disease, including the homeless, low-wage workers, and older adults among several states' governments, academics, and the media. The question we now face is how to transform these limited, temporary, and siloed efforts into a long-lasting new approach to health.

COVID-19 has also been a reminder that disease does not respect national boundaries. This makes pursuing health as a public good a global project, with countries working together to build a healthier world. The global initiative led by the World Health Organization, engaging 172 countries in discussions on the equitable manufacture of an affordable vaccine to people across the globe, is an early example of such efforts (WHO 2020).

There are, of course, tradeoffs to this approach. A redoubled investment in thinking of health as a public good must require, definitionally, a collective investment in forces that extend well beyond health. It requires recognizing that an investment in healthcare is not enough, and that health must inform the range of decision making that structures our society. There is something comforting in thinking health is just a matter of buying the right drugs and seeing the right doctors. But this has always been illusion, and COVID-19 has made that clearer than ever.

The healthcare-centered approach has been the dominant approach in the United States for decades and the country has been ill-served as a result. COVID-19 is in many ways a culmination of an individualized approach to health, and the disproportionate burden of COVID-19 in the United States perhaps reflects well the disproportionate reliance on the notion of health as a private good compared to other high-income countries. Treating health as a public good will require a wholesale rethinking of our individualistic approach to health and a change in the structures that follow from an approach that sees health as a public good. This would mean treating health the way many countries do parks, education, the post office, fire stations, the environment-in essence as a critical piece of the global commons supported by a collective investment, for the benefit of all. It would mean prioritizing the creation of health-generating systems instead of the current sickness management systems and investing in the preventive conditions of health-like safe housing, good schools, livable wages, gender and racial equity, clean air, drinkable water, a fair economy. It is particularly important to note that this thinking needs to be global. Calls to frame health as a global public good often focus on global investment in areas directly related to health such as global access to vaccines. We argue that such should expand beyond the health sector to include examining how global systems that regulate sectors beyond healthcare shape health outcomes in countries around the world. For example, understanding the role of climate change in shaping the health of the population adds urgency to global efforts to curb $\mathrm{CO}_{2}$ emissions. Another area for global action is re-examining global trade regulations that allowed transnational corporations to sell cheap sugary food and drinks to countries across the globe over the past few decades. This is an important area for intervention given that non-communicable diseases - many of which are driven by consumption of unhealthy food-contribute disproportionately to the global burden of diseases. All countries fundamentally need to see health as a public good, recognizing that pandemics do not respect national borders and as such it requires a universal approach to health to mitigate the consequences of any future pandemic.

Eventually, this pandemic will end. But the threat of pandemics will remain. The next outbreak-and there will be one-could well be deadlier, more infectious. Whatever form it takes, it will be helped along by the same conditions that helped COVID-19, if they are allowed to persist. It seems to us that there is no alternative if the world is to end this vulnerability, but to address health as a global public good.

\section{Compliance with Ethical Standards}

Conflict of interest This contribution is free from any conflicts of interest, including all financial and non-financial interests and relationships.

\section{References}

Abdalla, Salma M., Shui Yu, and Sandro Galea. 2020. Trends in Cardiovascular Disease Prevalence by Income Level in the United States. JAMA Network Open 3(9): e2018150. https://doi. org/10.1001/jamanetworkopen.2020.18150.

Bonaccorsi, Giovanni, Francesco Pierri, Matteo Cinelli, Andrea Flori, Alessandro Galeazzi, Francesco Porcelli, Ana Lucia Schmidt, Carlo Michele Valensise, Antonio Scala, Walter Quattrociocchi, and Fabio Pammolli. 2020. Economic and Social Consequences of Human Mobility Restrictions under COVID-19. Proceedings of the National Academy of Sciences 117(27): 15530-15535. https ://doi.org/10.1073/pnas.2007658117.

Braveman, Paula, Susan Egerter, and David R. Williams. 2011. The Social Determinants of Health: Coming of Age. Annual Review of Public Health 32(1): 381-398. https://doi.org/10.1146/annur ev-publhealth-031210-101218.

Deneulin, Séverine, and Nicholas Townsend. 2006. Public Goods, Global Public Goods and the Common Good. 18. Bath. https ://www.welldev.org.uk/research/workingpaperpdf/wed18.pdf. Accessed 2 Oct 2020 
Ettman, Catherine K., Salma M. Abdalla, Gregory H. Cohen, Laura Sampson, Patrick M. Vivier, and Sandro Galea. 2020. Prevalence of Depression Symptoms in US Adults Before and During the COVID-19 Pandemic. JAMA Network Open 3(9): e2019686. https ://doi.org/10.1001/jamanetworkopen.2020.19686.

Feachem, Richard G.A., and Carol A. Medlin. 2002. Health is Wealth. Nature 417(6890): 695. https://doi.org/10.1038/417695a.

Feachem, Richard G.A., and Jeffrey D. Sachs. 2002. Global Public Goods for Health. The Report of Working Group 2 of the Commission on Macroeconomics and Health.

Galbraith, John Kenneth. 1998. The Affluent Society. Houghton Mifflin Harcourt. https://books.google.com/books/about/The_Affluent_ Society.html?id=buihYlwXhuwC. Accessed 2 Oct 2020.

Galea, Sandro, and Salma M. Abdalla. 2020. COVID-19 Pandemic, Unemployment, and Civil Unrest. JAMA. https://doi.org/10.1001/ jama.2020.11132.

Galea, Sandro, Melissa Tracy, Katherine J. Hoggatt, Charles DiMaggio, and Adam Karpati. 2011. Estimated Deaths Attributable to Social Factors in the United States. American Journal of Public Health 101(8): 1456-1465. https://doi.org/10.2105/AJPH.2010.300086.

Han, Emeline, Melisa Mei Jin Tan, Eva Turk, Devi Sridhar, Gabriel M Leung, Kenji Shibuya, Nima Asgari, et al. 2020. Lessons Learnt from Easing COVID-19 Restrictions: An Analysis of Countries and Regions in Asia Pacific and Europe. The Lancet 0(0). https:// doi.org/10.1016/S0140-6736(20)32007-9.

Haynes, Hylton J.G. 2017. Fire Loss in the United States During 2016. www.nfpa.research. Accessed 2 Oct 2020.

Himmelstein, David U., and Steffie Woolhandler. 2016. Public Health's Falling Share of US Health Spending. American Journal of Public Health 106 (1): 56-57. https://doi.org/10.2105/AJPH.2015.30290 8 .

Johns Hopkins Coronavirus Resource Center. 2020. COVID-19 United States Cases by County. https://coronavirus.jhu.edu/us-map. Accessed 2 Oct 2020

Kamal, Rabah, and Cynthia Cox. 2018. How Has U.S. Spending on Healthcare Changed over Time? Peterson-Kaiser Health. https:// www.healthsystemtracker.org/chart-collection/u-s-spending-healt hcare-changed-time/\#item-health-spending-growth-has-outpacedgrowth-of-the-u-s-economy_2017. Accessed 2 Oct 2020.

Maani, Nason, and Sandro Galea. 2020a. COVID-19 and Underinvestment in the Public Health Infrastructure of the United States. Milbank Quarterly 98(2): 250-259. https://doi.org/10.1111/14680009.12463.

Maani, Nason, and Sandro Galea. 2020b. COVID-19 and Underinvestment in the Health of the US Population. The Milbank Quarterly 98(2): 239-249. https://doi.org/10.1111/1468-0009.12462.

Moon, Suerie, John-Arne Røttingen, Julio Frenk, and Leonard M. Miller. 2020. Global Public Goods for Health: Weaknesses and
Opportunities in the Global Health System. Health Economics, Policy and Law 12: 195-205. https://doi.org/10.1017/S174413311 6000451.

Smith, Richard D., Robert Beaglehole, David Woodward, and Nick Drager. 2003. Global Public Goods for Health: Health Economic and Public Health Perspectives. Oxford: Oxford University Press.

Smith, Richard D. 2003. Global Public Goods and Health. Bulletin of the World Health Organization 81(7): 475. https://doi. org/10.1590/S0042-96862003000700004.

Smith, Richard D., and Landis MacKellar. 2007. Global Public Goods and the Global Health Agenda: Problems, Priorities and Potential. Globalization and Health 3(1): 9. https://doi. org/10.1186/1744-8603-3-9.

Stein, Felix, and Devi Sridhar. 2017. Health as a 'Global Public Good': Creating a Market for Pandemic Risk. BMJ (Online) 358. August. https://doi.org/10.1136/bmj.j3397.

Tai, Don Bambino, Aditya Shah Geno, Chyke A. Doubeni, Irene G. Sia, and Mark L. Wieland. 2020. The Disproportionate Impact of COVID-19 on Racial and Ethnic Minorities in the United States. Clinical Infectious Diseases. https://doi.org/10.1093/cid/ciaa815.

The Concord Coalition. 2018. A Troubling Trend in Federal Investment Spending. Concord Coalition. https://www.concordcoalitio n.org/issue-brief/troubling-trend-federal-investment-spending. Accessed 2 Oct 2020.

WHO. 2020. 172 Countries and Multiple Candidate Vaccines Engaged in COVID-19 Vaccine Global Access Facility. WHO. 24 August. https://www.who.int/news-room/detail/24-08-2020-172-count ries-and-multiple-candidate-vaccines-engaged-in-covid-19-vacci ne-global-access-facility. Accessed 2 Oct 2020.

WHO Commission on Social Determinants of Health. 2008. Closing the Gap in a Generation: Health Equity Through Action on the Social Determinants of Health. Geneva. https://www.who. int/social_determinants/final_report/csdh_finalreport_2008.pdf. Accessed 2 Oct 2020.

World Bank. 2020. COVID-19 to Plunge Global Economy into Worst Recession since World War II. World Bank Group. https://www. worldbank.org/en/news/press-release/2020/06/08/covid-19-toplunge-global-economy-into-worst-recession-since-world-war-ii. Accessed 2 Oct 2020.

Publisher's Note Springer Nature remains neutral with regard to jurisdictional claims in published maps and institutional affiliations. 